\title{
BMJ Open Burden of visual impairment associated with eye diseases: exploratory survey of 298 Chinese patients
}

To cite: Guan X, Fu M, Lin $F$, et al. Burden of visual impairment associated with eye diseases: exploratory survey of 298 Chinese patients. BMJ Open 2019;9:e030561. doi:10.1136/ bmjopen-2019-030561

- Prepublication history and additional material for this paper are available online. To view these files, please visit the journal online (http://dx.doi. org/10.1136bmjopen-2019030561).

Received 20 March 2019 Revised 19 August 2019 Accepted 30 August 2019

\section{Check for updates}

C Author(s) (or their employer(s)) 2019. Re-use permitted under CC BY-NC. No commercial re-use. See rights and permissions. Published by BMJ.

${ }^{1}$ School of Pharmaceutical Sciences, Peking University, Beijing, China

${ }^{2}$ International Research Center for Medicinal Administration, Peking University, Beijing, China ${ }^{3}$ China Center for Health Development Studies, Peking University, Beijing, China

${ }^{4}$ School of Health Humanities, Peking University, Beijing, China

Correspondence to

Professor Luwen Shi; shiluwen211@163.com

\section{ABSTRACT}

Objectives To explore the economic burden, prevalence of catastrophic healthcare expenditure (CHE) and the quality of life (QoL) of Chinese patients with visual impairment (VI) associated with eye diseases.

Design A questionnaire survey from March to May 2016 by structured face-to-face interviews of patients with VI. Participants 302 patients who were diagnosed with moderate $\mathrm{VI}$ or worse in both eyes (visual acuity $<6 / 18$ ) were included, and 298 patients (98.7\%) who completed the survey questionnaires were eligible for the study. Outcome measures The economic burden was estimated by calculating participants' direct costs covered in 2015 and the definition of CHE was out-of-pocket (OOP) costs exceeding $30 \%$ of annual household income. QoL was weighed by health utility value using time-trade-off valuation techniques.

Results Annual average direct costs per patient caused by VI were US\$6988.6 \pm US $\$ 10834.3$, and $70.3 \%$ were direct medical costs of which only $26.9 \%$ were reimbursable by medical insurance. $32.2 \%$ of households that suffered from CHE, in particular, were less wealthy patients with VI living in rural areas and without medical insurance. The health utility value was rated at 0.65 on average, and patients with VI aged 51-57, living alone and insured by commercial medical insurance had relatively less QoL.

Conclusion Our study explored the economic burden and QoL of VI associated with patients with eye diseases in China, indicating a substantial economic burden and poor QoL. Preferential medical insurance policies should be designed in relation to people with VI to further reduce the health inequalities, avoid CHE and promote QoL.

\section{INTRODUCTION}

With a large rapidly-ageing population in mainland China, visual impairment (VI) is emerging as a significant public health concern. ${ }^{1}$ According to the World Health Survey (2003), one in five adults reported some degree of far visual difficulty. ${ }^{2}$ In 2015 , the number of people with moderate VI or worse was estimated to be 253 million globally. ${ }^{3}$ More than $80 \%$ of the global total of VI occurs in low-income countries, ${ }^{4}$ and $26.5 \%$ of the total of VI occurs in China. ${ }^{5}$ The prevalence of VI in China is $0.94 \%$, yet, for the

\section{Strengths and limitations of this study}

To our knowledge, this is the first study to explore the prevalence of catastrophic healthcare expenditure and QoL of Chinese patients with VI associated with eye diseases.

The face-to-face interviews were conducted in two tertiary general hospitals in Beijing, which might result in potential sample selection bias.

- There could have been recall bias because the data were self-reported by the patients

people older than 50 , this figure rises to $5.8 \%$. In Tibet, one of the highest and harshest human habitations on earth, the prevalence is $13.2 \%$. ${ }^{6-8}$

The main impact of VI is a diminished ability to perform daily activities, which often results in high health expenditures and the loss of independence. ${ }^{9}$ The total financial cost of VI worldwide was estimated to be $\$ 3$ trillion in 2010 or $\$ 4030$ per person who is visually impaired. ${ }^{10}$ In addition to the economic burden, VI also has extensive social ramifications in terms of participation in society, employment and quality of life (QoL). The WHO estimated that $1 \%$ of the total global burden of disease measured as disability-adjusted life years (DALYs) attributable to VI increased by $47 \%$ from 12.9 million DALYs in 1990 to 18.8 million DALYs in $2010 .^{1112}$

The burden of VI has been well researched in countries such as the USA, Australia and some European countries. ${ }^{12-14}$ However, little is known about the economic burden and QoL of patients with VI associated with eye diseases in China. Therefore, we undertook an explanatory survey to quantify the economic burden, identify the prevalence of catastrophic healthcare expenditure (CHE) and describe the QoL of Chinese patients with VI associated with ocular diseases. The results will provide primary information for 
policy-makers when allocating limited public insurance financial resources in mainland China.

\section{METHODS}

\section{Questionnaire design}

We conducted a questionnaire survey by structured faceto-face interviews of patients with VI. The study questionnaire included standardised items developed by reviewing related research as well as items developed by consulting ophthalmologists and pharmacists. The survey questionnaire included four parts: (1) sociodemographic information, (2) clinic-related information, (3) economic burden and (4) QoL.

\section{Sociodemographic information}

Age, gender, ethnicity, educational level, occupation, marital status, living status, current living place, medical insurance, personal income, household size and household income were included.

\section{Clinic-related information}

Healthcare service use, treatment history and level of VI were included. The level of VI was divided into three categories based on the WHO visual acuity (VA) categorisation principles: (1) moderate VI $(6 / 60<\mathrm{VA}<6 / 18)$, (2) severe VI $(3 / 60<\mathrm{VA}<6 / 60)$ and (3) total blindness (VA $<3 / 60) .{ }^{15}$ Causes of VI were noted using standard WHO methodology for surveys on VI. ${ }^{16}$

\section{Economic burden}

Economic burden was estimated by calculating participants' direct costs related to the diagnosis, treatment and follow-up care of eye diseases leading to VI and the expenses related to the vision loss/inability to see in the year 2015. Direct costs included direct medical costs, which were further divided into insurance covered and OOP parts, and direct non-medical costs.

\section{Quality of life}

The time trade-off (TTO) valuation technique is a commonly used QoL measurement that is understood by the majority of patients and shows good reproducibility. ${ }^{17}$ In our study, TTO determined the length of lifetime the respondent would be willing to forego to live in perfect health by asking, "Assuming you will only live for 10 years, what is the maximum amount of that time, if any, you would be willing to trade for a return to permanent perfect vision (1.0) during the years that remain?"18

The questionnaire was designed and optimised by ophthalmologists and clinical pharmacists in Beijing, China. After conducting a pilot field research study in a tertiary hospital in Beijing, all of the experts agreed that the questionnaire was valid. The items and descriptions of the survey questionnaire are shown in online supplementary appendix 1 .

\section{Recruitment and sampling}

Two tertiary hospitals in Beijing were recruited based on the volume of ocular outpatient visits using convenience sampling methods. Participants were eligible for inclusion in the study if they were diagnosed with moderate VI or worse in both eyes (VA $<6 / 18$ ) and were physically and mentally able to participate in the survey and agreed to participate in the study. We excluded participants who were pregnant, had a concomitant malignant disease or an inability to complete the questionnaire. Given the time required for each face-to-face interview and the volume of patients with VI visits in the both sample hospitals per day, we aimed to collect data from approximately 300 patients.

\section{Data collection and quality control}

A questionnaire survey was conducted from March to May 2016 by structured face-to-face interviews of outpatients admitted in ophthalmic department in Peking University Third Hospital and Beijing Hospital. These two hospitals accept most ocular outpatient visits in Beijing. All of the investigators were trained for standard processes via a workshop before implementation of the survey to minimise performance bias. In order to control ascertainment bias, the investigators read all the contents of the questionnaire during the face-to-face interviews to establish that patients with VI could hear and understand the questions. The interviews lasted approximately $0.5-1.0$ hours to collect detailed information. The researchers emphasised to participants that only vision-related costs were to be included after reading through every question in the economic burden section to ensure accurate recording of economic burden. Survey data were recorded on paper forms and translated using Epidata V.3.1. All patients were deidentified into a unique project sequence number during data analysis to ensure anonymity and control analysis bias.

\section{Outcome measures}

\section{Catastrophic healthcare expenditure}

CHE was defined as out-of-pocket (OOP) for healthcare over a year that exceeded a certain proportion of a household's income. This threshold had been defined in many ways. One of the most common definitions was OOP costs exceeding $30 \%$ of annual household income. ${ }^{19}$

\section{Quality of life}

Answers to the TTO questions were converted to utility value.

$$
\mathrm{Z}=(10-\mathrm{N}) / 10
$$

$\mathrm{Z}$ is the health utility value; $\mathrm{N}$ is the number of years that the respondents are willing to trade for a return to permanent perfect vision. Utility values were anchored on a scale between 0 (the preference for death rather than living in the patient's current state of health) and 1 (a perception of perfect health). ${ }^{17}$

\section{Statistical analysis}

Costs and income were assessed in Chinese yuan (CNY) and converted into US dollars (USD) uniformly based on exchange rates on 1 June 2016 ( $1 \mathrm{USD}=6.5889 \mathrm{CNY}$ ) to make the results more comparable with those of other published studies. 
STATA V.14.0 was applied to conduct the following statistical analysis: (1) descriptive analysis of the participants' demographic information, healthcare service use, insurance reimbursement rate, expenditures, CHE prevalence and QoL; and (2) bivariate $\chi^{2}$ test on the difference of CHE prevalence and QoL value between subgroups. The level of statistical significance was $\mathrm{p}<0.05$ (two-sided).

\section{Patient and public involvement}

Patients and the public were not involved in the development of the research questionnaire, outcome measures, design, recruitment and implementation of the study. The results will be disseminated through scientific journals.

\section{RESULTS \\ Description of demographic characteristics}

A total of 302 patients were included and 298 completed questionnaires were eligible for this study, yielding a response rate of $98.7 \%$. Patients' demographic data are shown in table 1 . The mean age in the sample was 65.4 , and there were slightly fewer men $(47.7 \%)$. Most of the participants were married $(85.2 \%)$ and living with family $(94.6 \%)$ and in urban areas $(71.8 \%)$. Of the total participants, $41.3 \%$ were covered by urban employee basic medical insurance, $23.8 \%$ by new cooperative medical scheme (NCMS), $14.1 \%$ by government medical insurance (GMI) and $13.4 \%$ by urban resident basic medical insurance (URBMI).

Of the visual-related health conditions reported, $58.4 \%$ had moderate VI, $28.9 \%$ had severe VI, and $12.8 \%$ were blind. Of the total participants, $71.8 \%$ had been suffering from VI for more than 1 year. Of the participants' VI, 26.8\%, $11.7 \%$ and $9.1 \%$ were caused by cataract, age-related macular degeneration (AMD) and vascular retinopathy separately, while $26.5 \%$ was caused by multiple ocular diseases. The annual personnel income and household income of the participants were US\$6266.4 \pm US $\$ 104030.2$ and US $\$ 13457.8 \pm$ US $\$ 167110.9$, respectively.

\section{Healthcare service use}

As shown in table 1, the average number of healthcare service use due to VI within 1 year was 9.7 outpatient visits, ranging from 4.8 visits (cataract) to 16.7 visits (glaucoma). The average number and length of inpatient hospital visits were 0.6 visit within 1 year and 2.7 days of hospital staying per visit.

\section{Direct costs}

The total direct medical costs were US $\$ 6988.6 \pm$ US $\$ 108340.3$ in 2015, including direct medical costs of US\$4909.8 \pm US $\$ 89810.7$ (70.3\%) and direct non-medical costs of US $\$ 2078.8 \pm$ US $\$ 44300.6$ (29.7\%).

As shown in table 2, of the direct medical costs, outpatient fees represented the largest costs at US\$3408.5
(69.4\%), followed by inpatient costs at US $\$ 1369.5$ $(27.9 \%)$. Except outpatient and inpatient costs, the participants also purchased drugs by themselves in retail pharmacies $(2.7 \%)$. Only $10.6 \%$ of the outpatient costs, $24.4 \%$ of the inpatient costs and $2.6 \%$ of the self-purchased drug costs were covered by the medical insurance. The average total OOP cost per patient was US\$4211.6 (85.8\%).

Direct non-medical costs occurred mostly due to longterm home care at US $\$ 1216.6(58.5 \%)$. Nutrition or assistive devices, food and accommodation, escort, transportation, and home modifications costs accounted for $13.3 \%, 8.5 \%, 7.7 \%, 7.2 \%$ and $4.7 \%$, respectively.

The specific costs among different groups are shown in online supplementary appendix 2.

\section{Insurance reimbursement rate}

As shown in table $3,28.1 \%, 9.5 \%, 2.7 \%$ and $26.9 \%$ of the outpatient, inpatient, self-purchased drugs and total direct medical costs caused by VI were reimbursable. However, the reimbursement rate decreased with the severity of VI (moderate VI $28.1 \%$, severe VI $27.0 \%$ and blindness 21.4\%) and increased with patient's economic status (lowest $15.0 \%$, lower $25.4 \%$, middle $28.7 \%$, higher $31.7 \%$ and highest $39.3 \%$ ). Rural patients received a lower reimbursement rate $(13.9 \%)$ as most of their medical insurance scheme was NCMS, which has a much lower reimbursement rate than other insurance schemes. The reimbursement rate of different diseases ranged from AMD $(23.9 \%)$ and glaucoma $(24.8 \%)$ to cataract $(26.7 \%)$ and multiple ocular diseases $(32.1 \%)$.

\section{Prevalence of CHE}

Patients with VI paid in direct medical costs an average amount equal to $111.5 \%$ of their individual annual income and $51.9 \%$ of their household's annual income. As shown in table 3, 32.2\% of households suffered from CHE caused by VI. The prevalence of CHE was generally correlated with the severity of VI (moderate VI 28.2\%, severe VI $31.4 \%$ and blindness 52.6\%; p $<0.05$ ). Patients living in rural areas generally had a greater risk of CHE compared with urban residents $(47.6 \%$ vs $26.2 \%$, $\mathrm{p}<0.001)$. Of all of the different types of medical insurances, CHE prevalence in patients without medical insurance and insured by NCMS ostensibly outweighed those insured by GMI and CMI (none 50.0\%, NCMS 47.9\%, GMI $16.7 \%$ and CMI 21.4\%; $<<0.01$ ). In relation to the patients' economic status, the less wealthy patients (those with lower or the lowest economic status) were much more likely to encounter CHE than wealthier patients $(\mathrm{p}<0.01)$. Patients with AMD $(51.4 \%)$ and glaucoma $(24.8 \%)$ had a much higher risk of CHE than those with cataract $(17.5 \%, \mathrm{p}=0.01)$.

\section{Quality of life}

As shown in table 3, the value of QoL was 0.65 on average and correlated with the severity of VI (moderate VI 0.69 , severe VI 0.65 and blindness 0.49 ; $\mathrm{p}<0.01$ ). Middleaged patients (51-70) had the poorest life quality $(0.58$, 
Table 1 General characteristics of sample of visually impaired patients in 2015

\begin{tabular}{|c|c|c|c|c|c|}
\hline Characteristics & n (\%) & Outpatient visit & Inpatient visit & Hospital stay per visit (days) & $\begin{array}{l}\text { Household income } \\
\text { (USD) }\end{array}$ \\
\hline Total & 298 & 9.7 & 0.6 & 2.7 & 13457.8 \\
\hline \multicolumn{6}{|l|}{ Age (years) } \\
\hline $19-50$ & $39(13.1)$ & 11.4 & 1.1 & 3.5 & 12696.0 \\
\hline $51-70$ & $125(41.9)$ & 10.8 & 0.6 & 2.6 & 13452.4 \\
\hline $71-90$ & $134(45.0)$ & 8.1 & 0.4 & 2.5 & 13684.4 \\
\hline \multicolumn{6}{|l|}{ Gender } \\
\hline Male & $142(47.7)$ & 10.7 & 0.6 & 2.7 & 14408.2 \\
\hline Female & $156(52.3)$ & 8.8 & 0.5 & 2.7 & 12592.6 \\
\hline \multicolumn{6}{|l|}{ Ethnicity } \\
\hline Han & 278 (93.3) & 9.4 & 0.6 & 2.7 & 12788.9 \\
\hline Minority & $20(6.7)$ & 13.9 & 0.7 & 2.1 & 22755.0 \\
\hline \multicolumn{6}{|l|}{ Educational level } \\
\hline Primary and below & $71(23.8)$ & 9.3 & 0.5 & 1.9 & 6945.0 \\
\hline Middle and high school & $159(53.4)$ & 9.9 & 0.6 & 2.7 & 13853.7 \\
\hline College and above & $68(22.8)$ & 9.6 & 0.7 & 3.3 & 19332.0 \\
\hline \multicolumn{6}{|l|}{ Occupation* } \\
\hline $\begin{array}{l}\text { Management } \\
\text { personnel }\end{array}$ & $32(10.7)$ & 12.1 & 0.8 & 2.3 & 15623.8 \\
\hline Professional personnel & $81(27.2)$ & 9.0 & 0.6 & 2.5 & 16599.2 \\
\hline General staff & 89 (29.9) & 10.1 & 0.6 & 2.2 & 14206.2 \\
\hline Farmer & $56(18.8)$ & 6.9 & 0.4 & 2.0 & 4707.6 \\
\hline Other professions & $11(3.7)$ & 14.0 & 0.5 & 2.9 & 28215.5 \\
\hline Unemployed & $29(9.7)$ & 7.7 & 1.0 & 3.1 & 11295.3 \\
\hline \multicolumn{6}{|l|}{ Marital status } \\
\hline Unmarried & $44(14.8)$ & 5.0 & 0.8 & 2.4 & 12740.7 \\
\hline Married & $254(85.2)$ & 10.5 & 0.5 & 2.7 & 13582.0 \\
\hline \multicolumn{6}{|l|}{ Living status } \\
\hline Alone & $16(5.4)$ & 7.9 & 0.6 & 5.6 & 6304.6 \\
\hline With family & $282(94.6)$ & 9.8 & 0.6 & 2.5 & 13863.6 \\
\hline \multicolumn{6}{|l|}{ Current living place } \\
\hline Urban & $214(71.8)$ & 9.7 & 0.6 & 2.7 & 15792.0 \\
\hline Rural & $84(28.2)$ & 9.6 & 0.6 & 2.6 & 7511.1 \\
\hline \multicolumn{6}{|l|}{ Medical insurance $†$} \\
\hline None & $8(2.7)$ & 18.1 & 1.4 & 3 & 18299.2 \\
\hline NCMS & $71(23.8)$ & 9.8 & 0.6 & 2.3 & 15099.4 \\
\hline URBMI & $40(13.4)$ & 8.1 & 0.4 & 1.8 & 11345.5 \\
\hline UEBMI & $123(41.3)$ & 10.2 & 0.5 & 3.6 & 6333.6 \\
\hline GMI & $42(14.1)$ & 7.9 & 0.5 & 1.8 & 31936.8 \\
\hline CMI & $14(4.7)$ & 5.5 & 1.5 & 1.4 & 4249.6 \\
\hline \multicolumn{6}{|l|}{ Level of VI } \\
\hline Moderate VI & $174(58.4)$ & 9.7 & 0.4 & 1.8 & 15021.5 \\
\hline Severe VI & $86(28.9)$ & 9.6 & 0.7 & 3.5 & 12308.5 \\
\hline Blind & $38(12.8)$ & 10.0 & 1.2 & 4.7 & 8898.5 \\
\hline
\end{tabular}


Table 1 Continued

\begin{tabular}{|c|c|c|c|c|c|}
\hline Characteristics & n (\%) & Outpatient visit & Inpatient visit & Hospital stay per visit (days) & $\begin{array}{l}\text { Household income } \\
\text { (USD) }\end{array}$ \\
\hline $3-6$ & $36(12.1)$ & 4.6 & 0.4 & 1.3 & 12948.3 \\
\hline $6-12$ & $48(16.1)$ & 7.5 & 0.5 & 2.8 & 9755.8 \\
\hline$>12$ & $214(71.8)$ & 11.1 & 0.6 & 2.9 & 14373.8 \\
\hline \multicolumn{6}{|l|}{ Cause of VI } \\
\hline Cataract & $80(26.8)$ & 4.8 & 0.3 & 1.5 & 10898.1 \\
\hline AMD & $35(11.7)$ & 12.1 & 0.3 & 1.4 & 12185.9 \\
\hline Vascular retinopathy & $27(9.1)$ & 8.9 & 0.9 & 2.1 & 14326.4 \\
\hline Glaucoma & $17(5.7)$ & 16.7 & 1.2 & 6.2 & 17850.1 \\
\hline Other eye diseases & $60(20.1)$ & 10.1 & 0.6 & 2.6 & 11511.3 \\
\hline $\begin{array}{l}\text { Multiple ocular } \\
\text { diseases }\end{array}$ & $79(26.5)$ & 12.0 & 0.7 & 3.8 & 16849.5 \\
\hline \multicolumn{6}{|l|}{ Economic status§ } \\
\hline Lowest & $59(19.8)$ & 10.0 & 0.6 & 2.3 & 2445.9 \\
\hline Lower & $59(19.8)$ & 7.7 & 0.8 & 3.9 & 6464.2 \\
\hline Middle & $60(20.1)$ & 8.3 & 0.5 & 3.3 & 10890.3 \\
\hline Higher & $60(20.1)$ & 14.2 & 0.5 & 1.4 & 15481.5 \\
\hline Highest & $60(20.1)$ & 8.4 & 0.6 & 2.4 & 32134.7 \\
\hline
\end{tabular}

${ }^{*}$ Occupation included current profession of unretired participants and former profession for the retired. Professional personnel were professional and technical personnel, that is, teachers, doctors, lawyers, engineers, among others.

†Public insurance included NCMS in the rural area, UEBMI, URBMI and GMI. NCMS was insurance for rural residents, UEBMI was for urban employees of urban enterprises, and URBMI was for those who were not employed or were flexible employees and children with urban household registration, students of urban schools and rural migrants who worked in cities. GMI, also called publicly funded free medical care, was insurance for some of the civil servants and personnel at public institutions. CMI was supplement of public medical insurance, purchased by respondents' employers or by themselves from an insurance company.

‡Duration of VI was defined by the period from the time during which the participants had their current visually impaired level. $\S$ Economic status was divided into five equal intervals based on household income per capita of the study participants. Lowest US $\$ 60.7,1274.9$; lower US $\$ 1365.9$ and US $\$ 2428.3$, middle US $\$ 2529.5$ and US $\$ 4097.8$, higher US $\$ 4249.6$ and US $\$ 6677.9$, and highest US\$7183.8 and US\$37942.6.

$\mathrm{AMD}$, age-related macular degeneration; CMI, commercial medical insurance; GMI, government medical insurance; NCMS, new cooperative medical scheme; UEBMI, urban employee basic medical insurance; URBMI, urban resident basic medical insurance; VI, visual impairment.

$\mathrm{p}<0.001)$ and patients living alone had a relatively poorer QoL than those living with family $(0.58$ and $0.68, \mathrm{p}<0.01)$. Of all of the different types of medical insurances, the health utility values of patients insured by CMI were significantly lower than those insured by URBMI $(0.49$ and $0.81, \mathrm{p}<0.01)$. Patients with multiple ocular diseases (0.56) had relatively poorer QoL than those with cataract $(0.76)$ and AMD $(0.72, \mathrm{p}<0.001)$.

\section{DISCUSSION}

This study provided primary information for the economic burden and QoL of Chinese patients with VI associated with ocular diseases, indicating a substantial burden of VI, with considerable variation among the different levels of VI, type of medical insurance and economic status.

In our study, annual direct medical costs per patient with VI associated with ocular disease were US $\$ 4093.1$ for moderate VI, US\$6321.8 for severe VI and US\$5453.9 for blindness, which were much lower than those in several previous studies in the USA, which reported mean annual direct medical expenses per patient to be US\$12175US $\$ 14029$ for moderate VI, US $\$ 13154-U S \$ 16321$ for severe VI and US\$14882-US\$24180 for blindness. ${ }^{12}$ This was understandable as the gross domestic product per capita of China was much lower than the USA in 2015 (China US\$8033.4 and USA US\$56803.5).$^{20}$ Direct medical costs occurred mostly due to outpatient visits, which was inconsistent with formal findings in the USA and Australia that direct medical costs occurred mostly due to hospitalisation. ${ }^{12}$ As for different diseases, AMD and glaucoma were reported to have the highest average annual direct medical costs in our study (US\$8821.8 and US $\$ 7414.8$ ), which were higher than those in studies of AMD in Thailand (US\$3604), ${ }^{21}$ and glaucoma in Germany (€814-€1195), UK (€457-1065), France (€313-€1002) and Italy $(€ 153-€ 791) .{ }^{1422}$ Previous studies demonstrated that even mild VI had a significant and independent impact on vision-specific functioning ${ }^{23}$ and diminished ability to perform activities of daily living alone, which led to long-term care for patients. Therefore, it was not 
Table 2 Annual direct costs of Chinese patients with visual impairment associated with ocular diseases

\begin{tabular}{|c|c|c|c|c|c|}
\hline Characteristics & $\begin{array}{l}\text { Mean } \\
\text { (USD) }\end{array}$ & $\begin{array}{l}\text { Median } \\
\text { (USD) }\end{array}$ & $\begin{array}{l}\text { Max } \\
\text { (USD) }\end{array}$ & $\begin{array}{l}\text { Min } \\
\text { (USD) }\end{array}$ & $\begin{array}{l}\text { Proportion } \\
\text { (\%) }\end{array}$ \\
\hline Direct medical costs* & & & & & 70.3 \\
\hline Outpatient costs & & & & & 69.4 \\
\hline Total & 3408.5 & 607.1 & 68296.7 & 0.0 & \\
\hline Drug & 2352.7 & 215.5 & 54637.3 & 0.0 & \\
\hline OOP & 3048.5 & 324.8 & 68296.7 & 0.0 & \\
\hline Inpatient costs & & & & & 27.9 \\
\hline Total & 1369.5 & 0.0 & 31871.8 & 0.0 & \\
\hline Drug & 408.8 & 0.0 & 12748.7 & 0.0 & \\
\hline OOP & 1034.8 & 0.0 & 31871.8 & 0.0 & \\
\hline Self-purchased drug costs & & & & & 2.7 \\
\hline Total & 131.8 & 0.0 & 4553.1 & 0.0 & \\
\hline OOP & 128.3 & 0.0 & 4553.1 & 0.0 & \\
\hline Total direct medical costs & 4909.8 & 1517.7 & 70573.2 & 0.0 & 100.0 \\
\hline Direct non-medical costs & & & & & 29.7 \\
\hline Long-term home care & 1216.6 & 0.0 & 28836.4 & 0.0 & 58.5 \\
\hline Transportation & 149.8 & 15.2 & 5463.7 & 0.0 & 7.2 \\
\hline Food or accommodation & 176.8 & 0.0 & 9106.2 & 0.0 & 8.5 \\
\hline Escort† & 161.1 & 15.2 & 6677.9 & 0.0 & 7.7 \\
\hline Nutrition or assistive devices & 277.1 & 0.0 & 4629.0 & 0.0 & 13.3 \\
\hline Home modifications & 97.5 & 0.0 & 6070.8 & 0.0 & 4.7 \\
\hline Total direct non-medical costs & 2078.8 & 440.1 & 33237.7 & 0.0 & 100.0 \\
\hline Total direct costs & 6988.6 & 2281.8 & 101079.1 & 45.5 & 100.0 \\
\hline
\end{tabular}

${ }^{*}$ Direct medical costs measured the cost of resources used for treating a particular illness and consisted of outpatient costs, inpatient costs and self-purchased drug costs. Outpatient costs were vision-related medical costs during outpatient visits, including registration fee, medical service fee, treatment fee, examination fee, drug expenses and medical supply expenses. Inpatient costs were vision-related medical costs during hospitalisation, including medical service fee, treatment fee, examination fee, surgery fee, drug expenses and medical supply expenses. Expenditures of medicine prescribed and purchased during outpatient and inpatient visits in hospitals were included in outpatient and inpatient drug costs, respectively. The cost of self-purchased drugs was the expense of the drugs that patients bought in pharmacies (not in hospitals) for their ocular disease treatment after the initial diagnosis.

†Cost of escort was meal, transport and accommodation costs encountered by patients' escorts during all outpatient or inpatient visits. OOP, out-of-pocket.

surprising that the highest direct non-medical costs came from long-term home care $(58.5 \%)$. A possible explanation for high nutrition or assistive device costs $(13.3 \%)$ in our study was that people in China were keen on buying nutrition or devices that usually advertised in the media, ${ }^{1}$ especially those visually impaired patients who rarely went out and had no other choices but to listen to TV for entertainment.

Our research showed that Chinese patients with VI had a relatively high financial burden, resulting in $32.2 \%$ of households suffering from CHE. Patients with VI paid in direct costs an average amount equal to $111.5 \%$ of their individual annual income and 51.9\% of their household's annual income, which indicated that the patients themselves are clearly unable to meet such substantial costs and that the exorbitant burden was too costly for even the entire household to maintain. In particular, for households that have a lower economic status, the discrepancy between costs and income was greater, which made them more vulnerable facing the CHE. Medical insurance plays a vital role in preventing patients from CHE by assisting to cover patients' medical expenses. However, our results showed that the average insurance reimbursement rate of Chinese patients with VI was low (26.9\%) and varied greatly between different insurance schemes. Patients without medical insurance were recorded to have the highest CHE prevalence, and patients insured by NCMS, with the relatively lowest reimbursement rate, ${ }^{24}$ had a substantially higher CHE prevalence than those with the highest reimbursement rate (GMI and CMI). Patients living in rural areas, who usually had a relatively low economic status and were insured by NCMS ${ }^{25}$ were ostensibly at a greater risk of CHE. This was the result of the 'urban-rural dual structure' of the medical insurance system in China, ${ }^{26}$ which showed a significant difference in coverage reimbursement scope, payment level and 
Table 3 Reimbursement rate, proportion of CHE and QoL by related characteristics

\begin{tabular}{|c|c|c|c|c|c|c|c|c|}
\hline \multirow[b]{2}{*}{ Characteristics } & \multicolumn{4}{|c|}{ Reimbursement rate $(\%)^{*}$} & \multicolumn{2}{|l|}{ CHE } & \multicolumn{2}{|l|}{ QoL } \\
\hline & Outpatient & Inpatient & SPD & Total & $\begin{array}{l}\text { Proportion } \\
\text { (\%) }\end{array}$ & $P$ value & Mean & $P$ value \\
\hline Total & 28.1 & 9.5 & 2.7 & 26.9 & 32.2 & & 0.65 & \\
\hline \multicolumn{9}{|l|}{ Level of VI } \\
\hline Moderate VI & 29.9 & 6.4 & 2.9 & 28.1 & 28.2 & 0.014 & 0.69 & 0.001 \\
\hline Severe VI & 26.9 & 14.8 & 2.9 & 27.0 & 31.4 & & 0.65 & \\
\hline Blind & 22.2 & 11.7 & 1.4 & 21.4 & 52.6 & & 0.49 & \\
\hline \multicolumn{9}{|l|}{ Cause of VI } \\
\hline Cataract & 29.5 & 4.3 & 2.3 & 26.7 & 17.5 & 0.010 & 0.76 & 0.000 \\
\hline AMD & 26.9 & 7.6 & 0.6 & 23.9 & 51.4 & & 0.72 & \\
\hline Vascular retinopathy & 24.8 & 9.4 & 1.7 & 25.2 & 37.0 & & 0.67 & \\
\hline Glaucoma & 32.4 & 19.7 & 0.0 & 24.8 & 41.2 & & 0.64 & \\
\hline Other eye diseases & 22.2 & 6.8 & 5.1 & 23.5 & 31.7 & & 0.59 & \\
\hline Multiple ocular diseases & 31.7 & 15.5 & 3.2 & 32.1 & 35.4 & & 0.56 & \\
\hline \multicolumn{9}{|l|}{ Current living place } \\
\hline Urban & 30.9 & 15.0 & 5.9 & 33.5 & 26.2 & 0.000 & 0.67 & 0.450 \\
\hline Rural & 27.9 & 9.2 & 2.5 & 26.5 & 47.6 & & 0.62 & \\
\hline \multicolumn{9}{|l|}{ Medical insurance } \\
\hline None & 0.0 & 0.0 & 0.0 & 0.0 & 50.0 & 0.008 & 0.64 & 0.003 \\
\hline NCMS & 14.2 & 4.9 & 2.3 & 13.9 & 47.9 & & 0.63 & \\
\hline URBMI & 24.2 & 6.9 & 4.3 & 21.6 & 25.0 & & 0.81 & \\
\hline UEBMI & 35.7 & 11.3 & 2.1 & 33.5 & 30.9 & & 0.63 & \\
\hline GMI & 38.5 & 14.5 & 2.6 & 38.0 & 16.7 & & 0.66 & \\
\hline $\mathrm{CMI}$ & 26.8 & 15.4 & 7.1 & 31.4 & 21.4 & & 0.49 & \\
\hline \multicolumn{9}{|l|}{ Economic status } \\
\hline Lowest & 15.0 & 4.7 & 3.1 & 14.7 & 54.2 & 0.001 & 0.59 & 0.559 \\
\hline Lower & 25.4 & 12.2 & 2.5 & 23.3 & 33.9 & & 0.66 & \\
\hline Middle & 28.7 & 8.3 & 2.9 & 31.3 & 26.7 & & 0.68 & \\
\hline Higher & 31.7 & 7.0 & 0.0 & 27.2 & 21.7 & & 0.73 & \\
\hline Highest & 39.3 & 15.4 & 4.9 & 38.0 & 25.0 & & 0.62 & \\
\hline
\end{tabular}

*Medical insurance reimbursement rate in our study was the percent of the whole year costs that is covered by insurance.

$\mathrm{AMD}$, age-related macular degeneration; $\mathrm{CHE}$, catastrophic healthcare expenditure; CMI, commercial medical insurance; GMI, government medical insurance; NCMS, new cooperative medical scheme; QoL, quality of life; SPD, self-purchased drug cost; UEBMI, urban employee basic medical insurance; URBMI, urban resident basic medical insurance; VI, visual impairment.

funding level. ${ }^{27}$ Besides, our study found that a higher severity level of VI caused higher direct costs but received a lower reimbursement rate, which resulted in a dramatically increased risk of CHE with the severity of VI. Furthermore, patients with AMD and glaucoma with a relatively low reimbursement rate had a heavier economic burden and were more likely to incur catastrophic spending. This result may be largely due to the high price of AMD treatment therapy, ${ }^{28}$ which also explains the highest fraction of outpatient costs of patients with AMD and limited drug covered by medical insurance. This situation was alleviated after the national pricing negotiations on two innovative but expensive medicines (Razumab and conbercept) in 2017, which eventually reached an average price discount of $18.74 \%$ by the pharmaceutical companies and $70 \%$ public medical insurance reimbursement rate by the Chinese government. ${ }^{29}$ Recommended management of glaucoma, which requires regular attendance of follow-up clinic visits, ${ }^{30}$ may explain the highest number of outpatient visit, inpatient visit, the longest stay per inpatient visit, as well as the high costs.

In addition to the economic burden posed by VI, our study also suggested that VI had a substantial negative effect on health-related QoL. Moreover, the life quality of patients with VI (0.65) in our study was worse than patients with cancer (0.92), mild stroke (0.9), gout (0.86), heart failure (0.78) and HIV/AIDS (0.70). ${ }^{31}$ This may be largely due to the significant association between 
VI and mental stress, such as anxiety, ${ }^{32}$ depression ${ }^{9}$ and cognitive functions. ${ }^{33}$ Among the study population, the utility value decreased dramatically with perceived total loss of vision, which was consistent with a study in rural Africa ${ }^{34}$ Previous studies have suggested that the utility values most highly correlated with the VA in the better seeing eye, and as the vision in the better seeing eye decreased, the corresponding utility value decreased. ${ }^{35}$ Patients with cataract reported the highest TTO utility value $(0.76)$ than those with other diseases, especially multiocular diseases $(0.56)$. One of the reasons for this is that cataract can be effectively treated by surgery, which is a disability-preventing and highly cost-effective intervention, ${ }^{36}$ and patients' TTO utility value could improve significantly after cataract surgery. ${ }^{37}$ Besides, living with family could slightly enhance the life quality rather than living alone because family members were often called on to provide physical and emotional support. ${ }^{38}$ However, unlike CHE, the life quality of visually impaired patients was not associated with their wealth and patients with one of the highest reimbursement rate insurances (CMI) had the poorest life quality in our study. Thus, efforts are needed to promote the access to adequate and effective treatment for visually impaired patients to alleviate their diseases and recover their sight. Moreover, the government should evade the inconvenience with daily living of the visually impaired patients by consciously redesigning the built environment, public facilities and services.

We spent 3 months in two tertiary hospitals to interview 298 individuals. Due to the limitation of movement for patients with VI in China, several limitations to this study should be noted. First, the study population is not fully representative of all the patients with VI in mainland China. Second, the face-to-face interviews were conducted in tertiary general hospitals in Beijing, which might result in a sample with higher education levels, income, treatment costs, better health insurance and more serious disease than the average level of all the patients with VI in China. Third, there could have been recall bias because the data were self-reported by the patients.

\section{CONCLUSION}

Our study provided primary information for the economic burden and QoL of VI associated with eye diseases of patients in China, indicating that, compared with people who were sighted, people with VI experienced greater difficulties with daily living, higher economic burden, greater chance of CHE and poorer QoL. The findings in this study suggested that preferential medical insurance policies should be designed of VI to further reduce health inequalities, avoid CHE and enhance the QoL.

Acknowledgements Our sincere appreciation to Professor Suodi Zhai and Chief Nurse Zheng Liu from the sample hospitals who provided great support for this study. The authors gratefully acknowledge all investigators participating in this study for their diligent work.

Contributors XG, FL and LS conceptualised and designed the study. FL and MF conducted the questionnaire survey. MF and DZ contributed to the analysis of the data. XG, LS, DV and MF conducted the final analysis and drafted the initial manuscript. All authors contributed to the critical revision of the paper and approved the final manuscript.

Funding This research received a grant from Beijing Novartis Pharma Co., Ltd. The funders had no role in study design, data collection and analysis, decision to publish, or preparation of the manuscript.

Competing interests None declared.

Patient consent for publication Obtained.

Ethics approval Ethics committee approval was obtained from Peking University's institutional review board (number IRB00001052-16003). All participants were informed by an information sheet and have signed the declaration of consent to participate in the study.

Provenance and peer review Not commissioned; externally peer reviewed.

Data availability statement Data of this study are available upon reasonable request from LS at shiluwen211@163.com. In order to ensure full anonymity, confidentiality and data protection for the participants, the full survey data cannot be made accessible to the public.

Open access This is an open access article distributed in accordance with the Creative Commons Attribution Non Commercial (CC BY-NC 4.0) license, which permits others to distribute, remix, adapt, build upon this work non-commercially, and license their derivative works on different terms, provided the original work is properly cited, appropriate credit is given, any changes made indicated, and the use is non-commercial. See: http://creativecommons.org/licenses/by-nc/4.0/.

\section{REFERENCES}

1. Zhang M, Song ZJ, Xia HZ, et al. Situation analysis of medication among geriatric chronic disease. Chin J New Drugs Clin Rem 2016;35:469-72.

2. Freeman EE, Roy-Gagnon M-H, Samson E, et al. The global burden of visual difficulty in low, middle, and high income countries. PLOS One 2013;8:e63315.

3. Bourne RRA, Flaxman SR, Braithwaite T, et al. Magnitude, temporal trends, and projections of the global prevalence of blindness and distance and near vision impairment: a systematic review and metaanalysis. Lancet Glob Health 2017;5:e888-97.

4. Taylor HR, Pezzullo ML, Nesbitt SJ, et al. Costs of interventions for visual impairment. Am J Ophthalmol 2007;143:561-5.

5. World Health Organization. Global data on visual impairment, 2010. Available: https://www.who.int/blindness/publications/globaldata/en/ [Accessed 23 February 2019].

6. Cheng J-W, Cheng S-W, Cai J-P, et al. The prevalence of visual impairment in older adults in mainland China: a systematic review and meta-analysis. Ophthalmic Res 2013;49:1-10.

7. Dunzhu S, Wang FS, Courtright $P$, et al. Blindness and eye diseases in Tibet: findings from a randomised, population based survey. $\mathrm{Br} J$ Ophthalmol 2003;87:1443-8.

8. National Bureau of Statistics of the People's Republic of China. The second National handicapped person sampling survey main data bulletin. Available: http://www.stats.gov.cn/tjsj/ndsj/shehui/2006/ html/fu3.htm [Accessed 21 April 2017].

9. Pascolini D, Mariotti SP. Global estimates of visual impairment: 2010. Br J Ophthalmol 2012;96:614-8.

10. Gordois A, Cutler H, Pezzullo L, et al. An estimation of the worldwide economic and health burden of visual impairment. Glob Public Health 2012;7:465-81.

11. World Health Organization. World health report 2004: changing history. Available: http://www.who.int/whr/2004/en/ [Accessed 2 May 2017].

12. Köberlein J, Beifus K, Schaffert C, et al. The economic burden of visual impairment and blindness: a systematic review. BMJ Open 2013;3:e003471.

13. Taylor HR, Pezzullo ML, Keeffe JE. The economic impact and cost of visual impairment in Australia. Br J Ophthalmol 2006;90:272-5.

14. Traverso CE, Walt JG, Kelly SP, et al. Direct costs of glaucoma and severity of the disease: a multinational long term study of resource utilisation in Europe. Br J Ophthalmol 2005;89:1245-9.

15. World Health Organization. Blindness and vision impairment. Available: https://www.who.int/en/news-room/fact-sheets/detail/ blindness-and-visual-impairment [Accessed 22 February 2019].

16. World Health Organization. Coding Instructions for the WHO/PBL eye examination record (version III). Available: http://apps.who.int/iris/ bitstream/10665/67896/1/PBL_88.1.pdf [Accessed 3 July 2019]. 
17. Calkins TE, Darrith B, Okroj KT, et al. Utilizing the time trade-off, standard gamble, and willingness to pay utility measures to evaluate health-related quality of life prior to knee or hip arthroplasty. $J$ Arthroplasty 2019;34:9-14.

18. Oppe M, Rand-Hendriksen K, Shah K, et al. EuroQol protocols for time trade-off valuation of health outcomes. Pharmacoeconomics 2016;34:993-1004.

19. Jan S, Lee SW-L, Sawhney JPS, et al. Catastrophic health expenditure on acute coronary events in Asia: a prospective study. Bull World Health Organ 2016;94:193-200.

20. The World Bank. GDP per capita (current US\$). Available: https:// data. worldbank.org.cn/indicator/NY.GDP.PCAP.CD?end=2015\& page $=5 \&$ start $=1993$ [Accessed 3 July 2019].

21. Dilokthornsakul P, Chaiyakunapruk N, Ruamviboonsuk $P$, et al. Health resource utilization and the economic burden of patients with wet age-related macular degeneration in Thailand. Int $J$ Ophthalmol 2014;7:145-51.

22. Rahman MQ, Beard SM, Discombe R, et al. Direct healthcare costs of glaucoma treatment. Br J Ophthalmol 2013;97:720-4.

23. Finger RP, Fenwick E, Chiang PP-C, et al. The impact of the severity of vision loss on vision-specific functioning in a German outpatient population - an observational study. Graefes Arch Clin Exp Ophthalmol 2011;249:1245-53.

24. Su D, Chen Y-chun, Gao H-xia, et al. Effect of integrated urban and rural residents medical insurance on the utilisation of medical services by residents in China: a propensity score matching with difference-in-differences regression approach. BMJ Open 2019;9:e026408

25. Dou G, Wang Q, Ying X. Reducing the medical economic burden of health insurance in China: achievements and challenges. Biosci Trends 2018:12:215-9.

26. Liu J, Chen H, Chen Y, et al. Exploring the relationship between migrants' purchasing of commercial medical insurance and urbanisation in China. BMC Health Serv Res 2018;18:679.

27. Han J, Meng Y. Institutional differences and geographical disparity: the impact of medical insurance on the equity of health services utilization by the floating elderly population - evidence from China. Int $J$ Equity Health 2019;18:91.
28. Kume A, Ohshiro T, Sakurada Y, et al. Treatment patterns and health care costs for age-related macular degeneration in Japan: an analysis of national insurance claims data. Ophthalmology 2016;123:1263-8.

29. Ministry of Human Resources and Social Security of the People's Republic of China. Notice on the inclusion of 36 kinds of drugs in the category $B$ of the National basic medical insurance, employment injury insurance and maternity insurance drug list. Available: http://www.mohrss.gov.cn/SYrlzyhshbzb/ shehuibaozhang/zcwj/yiliao/201707/t20170718_274153.html [Accessed 3 July 2019].

30. Lazcano-Gomez G, Ramos-Cadena MdelosA, Torres-Tamayo M, et al. Cost of glaucoma treatment in a developing country over a 5-year period. Medicine 2016;95:e5341.

31. Brown MM, Brown GC, Stein JD, et al. Age-Related macular degeneration: economic burden and value-based medicine analysis. Can J Ophthalmol 2005;40:277-87.

32. Wang $\mathrm{X}$, Lamoureux $\mathrm{E}$, Zheng $\mathrm{Y}$, et al. Health burden associated with visual impairment in Singapore: the Singapore epidemiology of eye disease study. Ophthalmology 2014;121:1837-42.

33. Ong SY, Cheung CY, Li X, et al. Visual impairment, age-related eye diseases, and cognitive function: the Singapore Malay eye study. Arch Ophthalmol 2012;130:895-900.

34. Briesen S, Roberts H, Finger RP. The impact of visual impairment on health-related quality of life in rural Africa. Ophthalmic Epidemiol 2014;21:297-306.

35. Brown MM, Brown GC, Sharma S, et al. Health care economic analyses and value-based medicine. Surv Ophthalmol 2003:48:204-23.

36. Lou L, Wang J, Xu P, et al. Socioeconomic disparity in global burden of cataract: an analysis for 2013 with time trends since 1990. Am J Ophthalmol 2017;180:91-6.

37. Kishimoto F, Naito T, Hasebe S, et al. Time trade-off utility analysis for surgical intervention in comitant strabismus, glaucoma, and cataract. Acta Med Okayama 2012;66:191-201.

38. Bambara JK, Owsley C, Wadley V, et al. Family caregiver social problem-solving abilities and adjustment to caring for a relative with vision loss. Invest Ophthalmol Vis Sci 2009;50:1585-92. 